Our project is based on four absolutely different and innovative steps.

1. Removal of electrons from bacterial cells by use of accurate potential difference electrodes.(as in the microbial fuel cell).

2. Rectify this current by use of a special device designed by us and get the output as $0.25 \mathrm{~V}$.

3. This obtained voltage is again applied to the microbial culture in biogas plant. By this accumulation of acetic acid takes place in the biogas fermenter.

4. The accumulated acid can be easily converted into $\mathrm{H} 2$ gas by the action of microbes from environment, using acetic acid as a selective component.

5. Further on passing this gas through hydrogen cells large amount of electricity can be generated as per our requirement.

The entire process takes place in biogas plant fermenter and hydrogen gas can be generated only when the $0.25 \mathrm{~V}$ voltage is applied to the culture in the plant's frementer. In the absence of voltage this plant produces $95 \%$ methane and not $70 \%$ as per the primitive plant did (a solid experimental proof for this). Thus pure methane as well as electricity can be generated by this plant by the switch over of a single switch. For implementation of this technique large funds are also not required and even a simple farmer can adopt this technique. Moreover the existing biogas plants in the country can also be modified by the introduction of certain metal electrodes in it. It can be concluded that this technique to certain extent can help in the development of rural areas in developing countries and make their dream of "developed nation" achived.

\title{
086 \\ Consumption patterns of energy in rural sector of Sri Lanka - Analysis based on Puttalam district
}

\author{
$\mathrm{J}$ Herath \\ Department of Agricultural Economics and Business Management, University of Peradeniya, Sri Lanka.
}

The energy crisis is prominent in developing countries where explosive populations are experienced with inefficient utilization of energy and poor technologies. Sri Lanka also fails in meeting the total national energy demand and presently seeking for alternatives while scrutinizing the potentials of efficient use of available energy sources of bio mass (mainly fuel wood), electricity and petroleum. While bio mass supplies $47.9 \%$ of the energy demand of the country, petroleum and hydropower contribute in $43.3 \%$ and $8.7 \%$ respectively. The main supply of bio mass is for domestic cooking activities in the rural sector. Out of the total electricity production of the country, around $39 \%$ is consumed by domestic sector and about $61 \%$ of the households are accessible for consumption of electricity. In provincial level, the western province shows the highest consumption of electricity and demand from other provinces is increasing drastically, mainly with industrial development activities and increasing population. However about $20 \%$ of electricity is wasted in its transmission. Although petroleum products are used mainly to supply energy for transport and industrial purposes, use of kerosene for lightening is about $48 \%$ of the country. While industrial and transport sectors consume $24.4 \%$ and $24.8 \%$ of whole the supplied energy, $51.1 \%$ is consumed by household, commercial and others. The inadequacy of energy at an affordable price is prominent in the rural sector, impeding the people in stepping into a quality life which stimulates better health practices, opportunities for education with information, and chances of income generating activities. However, complete studies with smooth analyses are imperative in reaching better policies in meeting rural energy demand.

The aim of this study was to investigate the present consumption pattern of fuel wood, Petroleum fuels and electricity as energy sources in the rural setting of Puttalam district. The results showed that more than $94 \%$ use firewood as the cooking fuel, which is freely available for them due to close proximity to the jungles and larger sizes of the home gardens. LPG consumption as a fuel was around $5 \%$. About $82 \%$ of the sample used electricity as the main energy source for lighting while the rest used kerosene. The average monthly expenditure (kerosene, LPG and electricity) for energy consumption was $7.44 \%$, and that was second only to the average food expenditure of $71.3 \%$. Rather, with including a minimum expenditure for firewood, considering the time cost of fire wood collection, expenditure on energy became much higher, implicitly implying the prevailing pressure on the remaining few jungles and forest covers. The econometric results of energy demand indicated that the increasing education level. monthly income and family size affect significantly on rapid growing demand for energy, especially cleaner energy.

Proceedings of the International Forestry and Environment Symposium 2016 of the

Department of Forestry and Environmental Science. University of Sri Jayewardene! ur.: Sri Lanka 